\title{
The Cinematic Depiction of Conflict Resolution in the Immigrant Chinese ${ }^{1}$ Family
}

The Wedding Banquet and Saving Face

\author{
Qijun Han
}

HCM 1 (2): 129-159

DOI: 10.5117/HCM2013.2.HAN

\begin{abstract}
Both emphasising dilemmas that have been confronted by the ChineseAmerican family, Ang Lee's The Wedding Banquet (1993) and Alice Wu's Saving Face (2004) highlight the image of homosexuality as incompatible with traditional Chinese family values. Through detailed narrative analyses of these two films with a focus on the structure of the plot, the key characters, and camera work, this article aims to answer the questions of how traditional Chinese culture continues to play into and conflict with the experiences of modern Chinese American families and how each film presents and resolves the tensions arising from a culture in transition. The article argues that the importance of studying the ways in which the protagonists try to come to terms with incompatible value systems, lies in the capacity of film to reveal the complex negotiation between tradition and modernity, as well as the socio-cultural specificity of the conceptions of modernity.
\end{abstract}

Keywords: Chinese-American family, homosexuality, narrative analysis, traditional Chinese family values

\section{Introduction}

From the mid-1980s onwards, a large number of filmmakers from Mainland China, Hong Kong, Taiwan, and the United States have expanded the visibility of Chinese-American family life. In particular, conflict between members of immigrant Chinese families has been a recurrent theme for 
many of these filmmakers, the conflict itself often stemming from the act of transnational migration and displacement. At the heart of these films, cultural traditions come up against certain pressures associated with modernity - ranging from urbanisation, commercialisation, self-affirmation and individuality, democratisation, rationalisation, and secularisation. The clash between modernity and traditional family values is more often than not set up through intergenerational conflicts within the families themselves: from the grandparents down to the grandchildren. Well-known examples of films operating along those lines include Wayne Wang's highly acclaimed Dim Sum: A little Bit of Heart (1985), Eat a Bowl of Tea (1989), The Joy Luck Club (1993) and A Thousand Years of Good Prayers (2007), and Ang Lee's "Father Knows Best" trilogy, Pushing Hands (1992), The Wedding Banquet (1993), and Eat Drink Man Woman (1994); a blend of the "ethnic and the exotic" which went on to earn him considerable international success. Other less well-known but still important movies exploring conflict within Chinese-American families include Peter Wang's A Great Wall (1986), Pam Tom's Two Lies (1989), Jue Sharon's My Mother Thought She Was Audrey Hepburn (1992), Hsu V.V. Dachin's My American Vacation (1999), Zheng Xiaolong's Guasha Treatment (2001), Huang Shuqin's Hi, Frank (2002), Lee Georgia's Red Doors (2005), Alice Wu's Saving Face (2005), and Frank Lin's American Fusion (2005). These films have tended to approach such familial conflict through what is known as "melodramatic excess".

Melodrama ${ }^{2}$ films have been an important medium for establishing the experience of Chinese immigrants in the United States. The act of crossnational migration brings up a broad range of issues; for instance, changing family structures and relationships, the displacement of cultural identities, and conflicts between Chinese-American communities and "outsiders". Much like Peter Brooks' argument that the emergence of melodramatic imagination in the West was closely tied to modernity and the rise of the middle classes, which in turn created a new "ethical" value system breaking down the oppressive social order, ${ }^{3}$ Chris Berry has identified a similar link between modernity and Chinese melodrama. ${ }^{4} \mathrm{He}$ has argued:

In so far as the emergence of the modern Chinese melodrama is coincident with the Chinese experience of modernity as a European import [...] we may therefore hypothesise that the Chinese family lunlipian ${ }^{5}$ is itself a modern and hybrid form that stages the tension between 'tradition' and 'modernity' as a tension between different models of subjectivity, with competing value systems for judging behaviour. ${ }^{6}$ 
The tension generated between traditional Chinese values and the needs of modern life has constituted the basic model of conflict in Chinese film production. Touching upon a wide range of topics - such as urbanisation, national identity, and morality - the family in relation to the tradition/ modernity debate was a major thematic concern in Chinese melodrama films in the 1920 and 1930 s. $^{7}$ It remains the case in contemporary Chinese cinema. Intergenerational conflict in immigrant families is brought to attention then and now, largely because of the filmmakers' shared interest in issues of family ethics since the advent of modernity. Melodrama thus can be viewed as a very powerful narrative tool addressing problems arising from the complexities of modern life. It is used as a form of cultural engagement to show how seemingly oppositional values can be bound together to evoke negotiation or transformation. In this article I argue that Chinese family melodrama, by bringing into focus the tensions between traditional Chinese culture and modern Chinese-American families, functions as a reflective and reactive discourse on the experience of modernity. To narrow the scope of discussion, I focus on two films: The Wedding Banquet (Ang Lee, 1993) and Saving Face (Alice $\mathrm{Wu}, 2004){ }^{8}$

The selection of these two films can be justified through their many points of similarity. First of all, both movies were produced (or co-produced in the case of The Wedding Banquet) by U.S. film producers and were aimed primarily at global audiences. Both have been screened at various international film festivals. In terms of narrative content, the similarities between these films are noticeable. Each tells the story of an immigrant Chinese family residing in the U.S.; each family is preoccupied with the control of sexuality in the service of traditional Chinese family values; each family has a powerful father figure and a young woman coming from the outside serving as an instigator of conflict resolution; and both present homosexuality as incompatible with traditional Chinese family values before offering a way out. Ang Lee's The Wedding Banquet addresses the incompatibility of homosexuality and family continuity. Likewise, Alice Wu's Saving Face presents gay identity against the Chinese perception of family face.

The Wedding Banquet and Saving Face make an effort to show negotiated family ethics. Ang Lee and Alice Wu bring the issue of homosexuality to the screen, a topic that many Chinese families run away from, as the perception of homosexual identity is in conflict with traditional family responsibilities such as ensuring family continuity and maintaining family reputation. There has been a growing interest in portraying homosexuality in contemporary Chinese cinema. Popular cultural images of homosexuality depicted in important movies such as Taiwanese filmmaker Tsai Mingli- 
ang's art-house trilogy Rebels of the Neon God (1992), Vive L'Amour (1994), and The River (1996), Farewell, My Concubine (Chen Kaige, Mainland China, 1993), East Palace West Palace (Zhang Yuan, Mainland China, 1996), Happy Together (Wong Kar-wai, Hong Kong, 1997), and Lan Yu (Stanley Kwan, Hong Kong, 2001), show that the issue of homosexual identity has become a shared concern among Chinese groups. Indeed, the presence of gay characters has drawn increasing scholarly attention including the recent publication of several book-length studies. ${ }^{9}$

Both The Wedding Banquet and Saving Face attempt to reconcile ethnic/ national identity and gay/lesbian identities. Although the more recent Saving Face has yet to generate much scholarship, the film The Wedding Banquet has been well studied, ${ }^{10}$ especially with regard to its homosexual themes, since it is generally regarded as the first "gay film" in transnational Chinese cinema. However, this article argues that there is much to be gained from situating the issue of homosexuality in these two films against the background of ethnic identity. Rather than a biological explanation, homosexuality and bisexuality are often portrayed as a Western phenomenon and a sign of the rejection of one's own ethnic culture in favor of acculturation to a more powerful "white" culture in the Chinese immigrant community in the United States according to Connie Chan's study, ${ }^{11}$ even though there has been a well-established literature which shows a tolerant tradition for homosexual love between men in ancient China. ${ }^{12}$ Homosexuality (accompanied by self-seeking and self-affirmation) and traditional Chinese family values and ethnic culture in the diaspora come together to provide melodramatic conflict in contemporary Chinese-American families as depicted in The Wedding Banquet and Saving Face. However, the flexibility of each family member in both films allows for a resolution of incompatibilities in homosexual and heterosexual practices, in turn giving room for individual expression while at the same time keeping the family intact. The Chinese family has generally been perceived as "tradition in the face of modernity", yet the cinematic construction of personal family stories in these films enables us to see how the ideology of a seemingly static tradition can actually accommodate new social needs. It is against this background that I situate the discussion of the representation of homosexuality in these two films.

Accordingly, I examine the family group as a collective protagonist, by treating each character separately in relation to their culturally and family defined roles, which steers family conflict towards a resolution. The two stories are analysed using narrative analysis. The storylines of the films including plots, characters, settings, and thematic developments are 
examined. Special attention is paid to the structure of the plot (especially with regard to the conflict between modernity and tradition as the key dramatic tension), the key characters, and the camera work. In so doing, the article aims to answer the following questions: How does traditional Chinese culture continue to engage and conflict with the experiences of modern Chinese-American families and how does each film present and resolve tensions from a culture in transition?

\section{Family Continuity and Sexuality: The Wedding Banquet}

In The Wedding Banquet, Mr. and Mrs. Gao are concerned about the marriage of their only son Wai Tung. Yet Wai Tung has kept the secret from his parents that he is gay and has lived with his Caucasian lover Simon for five years in New York. To prevent his parents from trying to send him more potential bride candidates, at Simon's suggestion Wai Tung arranges a paper marriage with his tenant Wei Wei. In return, Wei Wei would get her green card. What is not expected, however, is that Mr. and Mrs. Gao invite themselves over to get to know their daughter-in-law. They are heavily disappointed when it turns out that Wai Tung has planned to get married in an anonymous civil wedding ceremony at a sterile and unimpressive city hall followed by a small dinner in a Chinese restaurant. Interrupted by Old Chen, once the driver for General Gao during his army days and now the owner of the Chinese restaurant in New York, the simple wedding ceremony turns into a lavish wedding banquet. On the wedding night both Wei Wei and Wai Tung get drunk and end up having unprotected sex. This leads to Wei Wei's pregnancy and a subsequent family crisis. The conflict between family continuity and sexuality is eventually resolved in a way that can please both generations: while the parents get a baby to ensure the continuity of the Gao family, Simon also is surprisingly granted the father's secret recognition as a homosexual "daughter-in-law." In the end, homosexuality and family continuity are reconciled in this family melodrama, which perhaps can account for the critical success of The Wedding Banquet. The moral question posed by this film is not whether homosexuality is unacceptable in an ethnic Chinese family in its threat to the continuation of family lineage but rather how everyone can best meet their family obligations to ensure the family's continuation, despite an "undesired" sexual orientation in the Gao family. On the one hand, it requires an acceptance of homosexuality in the family. On the other hand, it needs every family member, including Simon, to realise the responsibilities that they may assume in their different roles. 


\section{Family Inclusion of Sexual and Ethnic Difference: Wai Tung and Simon}

Before the dramatic entrance of Mr. and Mrs. Gao, Wai Tung and Simon are a happy gay couple living together in the city of New York, which is a more convenient setting for the story to take place and for conflict resolution. Indeed, the act of situating the conflict in New York as a non-Chinese city makes a number of solutions possible. At the end of the film, the homosexual relationship is secretly approved - or at least accepted - by Wai Tung's parents. The problematic ethnic and sexual difference represented by Wai Tung and Simon is thus harmonised. As such, both characters are required to perform their assigned roles.

The Caucasian character Simon is provided with a traditionally "feminine" role, which leads the family to accept Simon as a good "daughter-inlaw" as the father remarks to Simon at the end of the film, "Thanks for taking care of our son". The first virtue Simon demonstrates throughout the film is his great capability to understand the Chinese family situation. When Wai Tung is troubled by his parents' attempt to find him a bride in Taiwan, Simon comes up with the idea of a marriage of convenience. One night Simon proposes the idea, which unsurprisingly is immediately rejected by Wai Tung. Wai Tung eventually is swayed by the benefits of a tax break, which indicates that the decision is not just made to pacify his parents.

According to an old tradition in Chinese society, the socially accepted situation for taking a second wife (or concubine) is when the first wife fails to produce a son. Wai Tung's marriage to Wei Wei - be it a fake one - could have been interpreted as a matter of betrayal and denial of his sexual identity and love. Yet Simon appears to be very supportive under these circumstances. He not only offers to invite Wai Tung's family and Wei Wei for dinner on the day of the registration of the marriage, but also plays the role of best man on Wai Tung's wedding with conviction.

However, exclusion and inclusion in Simon's case are not successive, but are concurrent and dynamically intertwined. On the one hand, Simon is joining every family meal and is frequently placed in the camera frame as part of the family. Moreover at the Wedding Banquet, Simon is sitting next to the new married couple together with the parents. It is purposefully constructed that Simon is seen as part of the family. On the other hand, at the moment when Wai Tung unwillingly kisses Wei Wei on her lips upon the insistence of the guests, Simon becomes the cultural, sexual and racial other in the performance of ritual actions - excluded from the rest who are present. This sense of exclusion persists throughout the sequence. Contrast- 
ing scenes visually express the idea of inside versus outside. The camera presents a close-up of Wai Tung kissing Wei Wei before it cuts to a medium close-up of Simon with his face in front of the camera. Then, a medium shot shows a group of cheerful guests. In the next shot, the camera frames Wai Tung and Wei Wei finishing their kiss with an unknown woman's happy face on the right side, and Simon's sad face on the left. He is placed in the periphery, evidenced by a number of single shots capturing his face. Mr. and Mrs. Gao appear in the frame when Simon is wiping the lipstick from Wai Tung's mouth with a napkin. Clearly, Simon is concerned with how the parents may feel, as the camera captures him looking into the parents' direction after this action. This defines the position of Simon - while he can be part of the Gao family, the Chinese community does not readily accept him.

Unsurprisingly, Simon is very upset later on to learn what has happened on the wedding night leading to Wei Wei's pregnancy. Nevertheless, Simon still accepts the consequences and is ready to be the second father of the baby. Simon's willingness to understand and cooperate defines him as a good foreigner in the context of Chinese culture. Furthermore, the implication of Wei Wei asking Simon to be one of the fathers of her baby is to secure the position of Simon in the family.

Second, Simon follows the code of Chinese family ethics by showing a great deal of filial piety. His efforts to win the approval of the parents is evidenced at various points: for instance, he acts nervously when first meeting Wai Tung's parents, much like the image of a new and shy daughterin-law raised according to Chinese customs. A small detail is revealing: Simon takes off the earring on his right ear before rushing to open the door for the parents; meanwhile, the background wall is filled up with Chinese paintings and calligraphy. Simon owns the apartment, yet in order to please the parents he removes from the house the objects that could appear inappropriate to the parents. Moreover, he buys very considerate gifts for the parents: a blood pressure monitor for Mr. Gao and protein facial cream for Mrs. Gao. Clearly his attempt to speak Chinese is also a way to show his respect, and later on it is comforting for the parents to know that Simon can cook very delicious Chinese food and perform domestic chores of house maintenance and caring for Wai Tung.

These moments, as Shu-mei Shih reads them, can be viewed as occasions where Simon is vying with Wei Wei "for the love of Wai Tung in a heterosexual economy of desire" ${ }^{13}$ However, the strategy for coping with ethnic difference and reducing conflict is overlooked in this reading. I should also point out that Lee quite deliberately presents an ideal image of 
the Chinese daughter-in-law to the traditional Chinese parents and to the audience as well. While Lee clearly sets up the conflict between the cultural and racial difference represented by Simon and the traditional Chinese family structure, norms and customs, he also creates room for resolution by minimising the differences.

The character of Wai Tung is transgressive in several respects. First, the sportive and masculine characteristics demonstrated by Wai Tung constitute a break with classical Hollywood cinema's representation of Chinese men. ${ }^{14}$ The film starts with Wai Tung working out at the gym, which is different from the common Western image of the quiet and effeminate Chinese. In the film, he appears to be a successful businessman, as Wei Wei remarks, "Simon is so lucky to have such a handsome and rich boyfriend."

Moreover, his homosexual orientation and his relationship with Simon suggest that his character is not fully embodied in traditional Chinese codes. He remains the perfect son in his parents' eyes, until he discloses the secret that he is gay to his mother. As a woman who has always placed importance on the patriarchal order, the mother finds it hard to take in the news and she questions her son, "Did Simon lead you astray?" "How can you be so confused?" "Didn't you have girlfriends in college?" The mother's remark from another perspective also reaffirms the point made earlier that homosexuality is commonly viewed among the Chinese as a cultural phenomenon, as the mother believes that Wai Tung is tricked into homosexual practices by Simon, an American man. In the end, she makes her son promise that it will remain a secret to the father for the news apparently "will kill him." ${ }^{15}$

Finally, in correspondence with his identity as a Chinese man living in the United States, he has been exposed to both Chinese and American cultures. He was raised in an environment in which traditional values were stressed, but he later lives in a society that embraces the modern values of self-orientation, self-expression, and self-determination. The film shows the burden and shame that a gay Chinese man has to bear. The sense of guilt and duty requires Wai Tung to hide the secret from his parents and to cooperate with the demands of his parents: meeting the ideal candidate arranged by his parents, entering into a heterosexual marriage with Wei Wei, and performing a traditional Chinese wedding. If Simon's sexual and ethnic difference is harmonised by his acceptance of the complexity of Chinese family values and his efforts to be a good "daughter-in-law", then Wai Tung's compromise is a clever means to smooth over any tensions between his parents and himself. 


\section{The Omnipotent Power of Patriarchy}

The eventual inclusion of Simon and Wai Tung in the family is realised through patriarchal flexibility. Despite his silence, the father occupies an important role in family matters. The centrality of the father figure is expressed through cinematic mise-en-scène. The camera grants him a position of power in the family through the shot of the dining table sequence. In the scene where the family has its first dinner together, the father is placed at the center of the frame. Most of the time, he is centrally positioned, facing the camera. When he comments on the quality of the food, everyone shows his or her respect. Similar scenarios occur throughout the film.

Even though Mrs. Gao is doing most of the talking, the father's words are seen as law in the family. The patriarchal power is invisible yet omnipotent. "I watch, I hear, I learn", the father says upon deciding what is best for the family. The father appears as the cultural carrier or guardian, supervising family relations and ensuring the succession of the family line. Accordingly, the function of the father should not simply be seen as an intervention designed to eliminate homosexuality.

As the film addresses both domestic and international audiences, critics interpret the father figure in very different ways. Ming Dariotis and Eileen Fung interpret the father's reaction as a way to distill otherwise homophobic formulations depicted in the film. ${ }^{16}$ Shih argues that the patriarchal flexibility shown by the father caters to both national and international needs. ${ }^{17}$ On the level of ethnic framing, Berry and Farquhar suggest that Mr. Gao's acceptance of Simon is deeply rooted in the Chinese strategy of inclusion so long as homosexuality and family continuity can be reconciled. ${ }^{18}$

While I do not disagree with these observations, I believe that the actual solution adopted by the characters, and in particular the approval of the father, in fact moves beyond ethnic bounds. In this regard, patriarchy is no longer fixed, monolithic, and timeless; instead, it requires being up-to-date in the same way that Jeroen de Kloet has argued that Lee's films can be read as a continuous reworking of Chinese family ideology. ${ }^{19}$ In the case of The Wedding Banquet, while family continuation still functions as one of the ground rules, the application of patriarchal power has various expressions. If that is the case then, how is the family crisis of patrilineal lineage resolved from the perspective of Mr. Gao?

Mr. Gao in Mrs. Gao's words "was a general commanding tens of thousands." Throughout the film, the social status of the father is made clear through visual construction: the father stands in old military style which forms a contrast to the posture of the other characters; he sits firm as a 
wall at the table, the former soldier greets him with a deep bow, and the tables are full of guests who have come from Taiwan to participate in the wedding. The father is already positioned as a powerful character that not only once commanded an army but also is still commanding the family. Thus, he plays an important role in forming the social and family order. The setting echoes the remark made by Ang Lee who appears as an extra during the wedding, "You're witnessing the results of five thousand years of sexual repression."

I argue that the patriarchal flexibility demonstrated by Mr. Gao is made possible because of the father's own experience. Clearly Wai Tung is not the only victim of the vicissitudes of Chinese cultural norms about family duties and sexuality - his father too once faced a similar fate. As Mr. Gao confesses to Wai Tung during a father-son conversation, his participation in the military was not out of nationalism but a matter of personal interest. Mr. Gao chose to join the army to escape from a marriage arranged by his parents. In an economy of patriarchal succession, he eventually also fulfilled his family role by getting married and having children. The act of sharing a long-kept secret in fact unites the father and son, as both characters have resisted an imposed marriage by their parents. The affective bond is thus formed between two generations with similar experiences.

This scene to some extent shares a resemblance with another scene towards the end of the film: when the father discloses a big secret to Simon. The father shows his approval by speaking English and giving Simon a red envelope filled with money. The camera shows the father and Simon from behind, placing them in the same frame throughout the conversation. The audience is refused access to their faces and therefore has to imagine the inner world of the characters without getting clues from their facial expressions. In this way, the father also literally keeps his face.

The complex father figure reflects Lee's attempt to negotiate traditional Chinese family values in a changing social context. As long as the perpetuation of the family line is realised and the homosexual romance between Wai Tung and Simon remains a secret, the family conflict can be resolved. The final image of the father raising his arms when being stopped by the security officer is ambiguous. Rey Chow interprets this gesture as "I am unarmed - I cross borders as an enlightened world citizen". ${ }^{20}$ If we agree that raising both hands can mean full approval and support, then what does Mr. Gao agree with - the family continuity, the rebel liberation, or a world in negotiation? 


\section{Women's Roles Assigned: Mrs. Gao and Wei Wei}

While on the one hand The Wedding Banquet is liberal in the sense that a new type of family is formed - an interracial gay couple is living together with a Chinese immigrant woman - the film in fact reinforces the patriarchal structure of the family, evidenced first of all by the feminine role of the "daughter-in-law" occupied by Simon and second by the two female characters, namely, Mrs. Gao - the mother, and Wei Wei - the "official" daughter-in-law.

The position of women in this family, as well as the division between male and female groups, is made clear through framing. At the dinner table, while Mrs. Gao and Wei Wei are placed on the one side of the father, Wai Tung and Simon are sitting on the other side. Likewise, the two female characters are often put in the kitchen, performing domestic duties, despite the fact that Wei Wei cannot really cook. As a result, the internal division within the frames in fact creates an imposed opposition between male and female groups.

The camera constructs the divisions. Motivating this division is a specific ideology related to the position of women within both family and society. In the scene where old Chen is discussing a wedding banquet for the couple with the father, the camera focuses solely on the males and only few shots involve Wei Wei, the actual central figure of the wedding. Furthermore, the fact that Wei Wei only appears in the frame at a very late stage indicates her position in the family. The symmetrically composed shots of female and male characters expose the traditional setting in which men and the older generations are the decision makers.

Following patriarchal logic, Mrs. Gao is assigned the role of promoting a patriarchal agenda, especially in relation to how women should behave in the family; Wei Wei functions more like a "surrogate mother". In this respect, one may argue that The Wedding Banquet after all does not represent a general course of family liberation, but rather a set of strategies for coping with different needs. In the spirit of the family, this is designed to satisfy everyone; yet it is sometimes achieved at the expense of the less privileged.

The film begins with Mrs. Gao's voice on tape, which seems to make her role more important. However, as the audience comes to notice, the mother is in fact speaking for the father, who expects the only son of the Gao family to get married and to produce children. Carrying out the important mission of protecting the family lineage, Mrs. Gao is first sending the taped message, then an ideal bride candidate, and finally herself to the United States. 
On the first day of their arrival, while the father appears to be silent most of the time, the mother acts as a cultural translator, who is committed to sustaining cultural heritage. Besides money and jewelries, the mother gives her new daughter-in-law an expensive traditional Chinese wedding dress, which had been brought from Mainland China to Taiwan. Later, upset by the quick city hall wedding arranged by Wai Tung, the mother bursts into tears. To her, this American wedding clearly is a violation of the traditional rituals.

The importance of protecting the family lineage is exemplified by the mother's dramatic reaction to Wei Wei's decision to have an abortion. It would be logical to assume that the mother lacks education and therefore lacks freedom to make her own decisions, as she refers to Wei Wei as a modern, well-educated, and independent woman that she envies. Yet on the other hand, she is a firm believer in traditional Chinese family values, which is shown by her persuading Wei Wei to keep the baby, as "husband and children are most important to a woman." To a large extent, the mother's notion of family values conforms to the conventional social norm, but she also bears the culturally defined role of "mother" and "wife" in accordance with Confucian ideals.

Wei Wei is interpreted by some scholars as cheap "labor" that is dependent on global capital, ${ }^{21}$ as she attempts to get grounded in the world she desires through agreeing to enter into a marriage agreement with Wai Tung. However, such an interpretation simplifies the complexity of Wei Wei and undermines the role of Wei Wei in our understanding of Chinese culture. To begin with, Wei Wei is an artist from Shanghai, who is struggling to survive in a foreign country. Her situation is precisely what she describes to Wai Tung and Simon, "Really, I can't last any longer. No money, no job, and no green card", after she loses her job as a waitress. In stark contrast to Simon, she is not a homemaker either, as she cannot cook or run a household. She has a very insufficient grasp of the English language, illustrated by the truncated and comical wedding vows at the city hall. On the other hand, one can hardly deny that Wei Wei is an aspiring artist. Despite her difficult situation, she is determined to succeed in her profession. She comments eloquently on Mr. Gao's classical calligraphy decorating on the first day of the parents' arrival. Through her lack of English proficiency, she is less assimilated into American culture. Compared to Wai Tung, she is in fact much closer to Chinese tradition, and therefore, to Mr. and Mrs. Gao. All the time, she is conscious of playing a charade. She is placed in a dilemma where her guilty conscience cannot be eased. This is made evident by the scene in which Mr. Gao's wedding speech induces Wei Wei to start crying and the entire group rushes her off to prevent ruining the bride's makeup. 
It is instructive to look into Wei Wei's handling of her pregnancy/abortion by taking into account the renqing (translated as human feelings or sentiment) side. Tightly linked to the Confucian norms of social responsibility and appropriate behaviour, renqing is one of the common social rules used to regulate Chinese interpersonal relationships. As a result of the renqing behind Wei Wei's actions, the crisis of the pregnancy/abortion is dealt with in a sentimental way. Being moved by Wai Tung's parents, Wei Wei comes to miss her own family in China. Even though the marriage was conceived as a trade, the relationship between Wei Wei and the Gao family is based on the "reality" of family ties. From Wei Wei's perspective, she has in fact completed a kind of homecoming through her intimate relationship with Wai Tung's parents.

To make sure that the audience does not miss the sentimental touch, Lee inserts a scene in which Wei Wei is persuaded by the mother not to abort the baby. The night before the scheduled abortion, Wei Wei decides to return everything she has received from the parents because these belongings carry with them deep emotional meanings. In the mother's refusal to accept them, the familial relation is redefined as the mother asks, "You can return these materials, but what about the love we have given to you?" This simple question is self-explanatory. At the heart of the question is a kind of plea, a plea to keep the baby, so that the Gao family will continue to exist. Such a plea is made on the basis of mutual love and affection. For the parents, the wedding is legitimate and real no matter what, so the unborn child is not affected by the situation between Wei Wei and Wai Tung. Thus, the deep attachment shown by the parents to the unborn baby constitutes an obstacle in Wei Wei's abortion, which eventually leads her to change her mind.

Whether by means of characterisation or plot, what has been unraveled is the deep longing for home and family, be it in the form of protection and preservation of the Gao's family lineage, the desire expressed by Wai Tung and Simon that racial and sexual differences should be accepted in the family, or Wei Wei's empathetic sensibility for the parents. The seemingly happy ending in the film is a product of a collective compromise.

\section{Family Reputation and Sexuality: Saving Face}

The story of the movie Saving Face spans three generations in a Chinese American family. While the young Chinese American surgeon Wil (Michelle Krusiec) lives in Manhattan, representing many different cultures, her 
mother Ma (Joan Chen) and grandparents live in Flushing, the second largest Chinatown in New York City. The plot interweaves and juxtaposes two important secrets. Ma, a 48-year-old widowed mother, is banished from the family when her father discovers that she is pregnant. Refusing to reveal the identity of the baby's father, Ma is forced to move to Manhattan to live with her daughter Wil, who at the same time attempts to hide a secret from her mother. Wil is in love with the daughter of her boss at the hospital, the dancer Vivian (Lynn Chen). Whereas Ma is pressured by her father to marry Cho, a sweet but boring man, as a condition to be allowed to return to Flushing, she pressures her daughter Wil to find a boyfriend, when in fact she already knows that Wil is a lesbian and that Vivian is her girlfriend. After a number of confrontations taking place within and outside the family, both Ma and Wil achieve a fulfilling sense of personhood.

The movie is commonly seen as a romantic comedy that deals with a lesbian relationship. Stephen Holden (2005) of The New York Times referred to the movie as an "amiable romantic comedy". ${ }^{22}$ Indeed Saving Face can be read as a light-hearted comedy and a tender romance. Yet, the idea of generational conflict that the movie rests on could also characterise Saving Face as a typical family melodrama. The important elements of the complex and conflicting dilemmas confronted by both Wil and Ma constitute the core of melodrama. The theme is made clear by the suggestive title Saving Face. Accordingly, the film focuses on preserving family reputation and the accompanying issue of Chinese identity in the context of diaspora and migration. Thus, it is not about an individual's identity but rather about family reputation. In order to protect the family's face, the mother and daughter are both supervised by the patriarchal figure in the family and by the overseas Chinese community. Their identities are formed as a consequence of social configuration and family roles. Believing that their sexuality is not a matter of private concern, both Wil and Ma are forced into sexual restraint.

The name of the film is obviously in reference to the social concept of "face". A family's reputation is highly valued in Chinese culture. ${ }^{23}$ It is not unusual to presume that the existence of others is an inherent part of one's struggle for self-definition. Anchored in two senses - self presentation and social evaluation - the notion of face involves taking the perspective of other people and evaluating oneself on the basis of how others would. If saving face is fundamentally a process of the structuring and maintaining of social roles, then the social input - as a cluster of behaviour stimulating such awareness - may explain the very existence of a "closet". The idea of the "closet" used here refers both to Western sexual discourse ${ }^{24}$ and the 
discourse of traditional Chinese culture. Metaphorically speaking, openness is less a feature of Chinese culture; rather, the "closet" works better as a strategy to keep "face" and Chinese identity. As the famous Chinese proverb "the skeleton in the closet cannot spread" manifests, issues related to losing face should remain private and stay in the closet.

By depicting the tensions between generations within and outside the family, Alice Wu's Saving Face explores how the Chinese-American community has defined and reinforced the closet, and how individuals struggle to hide behind or come out of the closet. I deploy the concept of the closet in my analysis of the sexual themes and gender issues articulated in this particular film. Michael P. Brown has explored a nested series of spatial scales derived from the notion of closet: the body, the city, the nation, and the world. He argues that "the closet" used to describe the concealment of homosexuality serves as an instance of a spatialised metaphor that "alludes to certain kinds of location, space, distance, accessibility and interaction." ${ }^{25}$ Accordingly, I examine the spatiality of the closet in relation to "saving face" in the film: the body, as the first core of the nested matrix proposed by Brown. I discuss the two main characters' bodies, and in particular, the relationship between body and identity. In Saving Face, Wu, by means of the strategic use of the body throughout the film, connects the body with those fragments of identity. To a certain extent, the exploration and discovery of identity is accompanied by the liberation of the body.

If The Wedding Banquet is still told from the dominant male perspective, then what is privileged in Saving Face is a female point of view. The male figures are mostly peripheral and become a merely supporting cast. The mother-daughter relationship occupies a dominant role, as the film centers on female protagonists (Wil, Ma, and Vivian), and emphasises the changing female consciousness arising from their development. Identity appears to be an evolving process that is evoked and defined by one's relations with others. As a common narrative strategy, mothers are used to trigger their daughters' drive for identity. Yet in this film, it is the triangle relation involving Ma, Wil, and Vivian - that serves to shape and motivate the development of the identity of Ma and Wil.

\section{The Closeted Daughter}

The film narrative consistently points to the dilemma that Wil, as a lesbian Chinese woman, has to face. Wil's life is divided between her career as a promising Manhattan surgeon and her family living in Flushing. Before she 
becomes involved with Vivian, her life is punctuated with matchmaking dances with unmarried men set up by her mother. However, her life is abruptly changed after Ma shows up pregnant on her doorstep. Wil is forced to combine two very different worlds embodied by a Chinese mother who insists on her daughter's heterosexual marriage and by her Americanised lover who wants Wil to come out of the closet. Similar to The Wedding Banquet, where Lee arranges Wai Tung to marry a Chinese woman in order to satisfy his parents' needs, Wu explores lesbianism in Saving Face by depicting the closeted Wil as hiding behind her job and the occasional heterosexual date set up by her mother. In this way, Wil is able to keep her "secret" from her mother. Nevertheless, Wil's sexual identity is progressively revealed in her relationship with Vivian.

The opening scene of this film is rather illuminating: in a high-angle shot, the camera looks down at an Asian female figure with her hand on the sink and her arms wide open; more interesting is that she is wearing a white facial mask. Only at a later stage in the film is the audience informed that using a white mask is actually an idea from Wil's mother. The camera focuses on the whiteness of this image: the mask, the t-shirt that she is wearing, and the sink.

The camera then captures the same woman rushing downstairs with her face almost invisible. The profession of this woman is made clear by the next scene in which she is wearing a blue medical coat and her face is covered by a white mask. The camera frames her right hand holding the scissors; meanwhile, another hand appears in the frame to cut the thread. She is placed in the foreground and a male figure is standing in the background observing the surgery. The film then cuts to a long shot of two senior doctors - including the continuously present man - exchanging their views on this young woman, who according to them has a promising future as a chief surgeon.

In all of these scenes, the camera actively keeps the face in the center of the frame. For the most part, the camera gazes upon the face of the woman, whether it is covered or not. It is interesting that within these scenes, the "whiteness" stands out in relation to the social norms of what beauty is and what marks success. While the first scene focuses on the construction of whiteness as a beauty standard, the hospital scene on the narrative level serves to connect whiteness with professional success. The face of the woman in both scenes is covered behind a white mask.

It is through the conversation of the colleagues, as well as the conversation between the mother and another Chinese woman, that we as viewers get to know Wil. Wil's homosexual identity as a "secret", on the other hand, 
is progressively revealed and realised through her interaction with Vivian, who appears to be a very charming and assertive female figure. It is interesting to note that both of their careers are closely related to the body. Whereas Wil is a doctor who performs surgery, Vivian is a ballet dancer who does modern dance. Influenced by their own professions, Wil and Vivian have different views on their bodies. In stark contrast to Wil, Vivian comes from a less conventional family where she can be open about her sexual identity. She pursues her own professional interest, and her broken Chinese suggests that she is less constrained by Chinese culture. Wil, on the other hand, is still bound by a symbolic order that she is hesitant to break loose from.

The first conversation between Wil and Vivian takes place in front of a hospital vending machine. Vivian flirts with Wil. When discussing the choice of snacks, she leans over close next to Wil's body and says, "Sometimes your body knows what you really want." The camera captures a shot of Wil and Vivian gazing into each other's eyes. The mutual attraction between these two characters is noticeable. Interestingly enough, while the camera frames Wil and Vivian together, there is an illuminated "Exit" sign behind them. For a woman who is in a closet vis-à-vis her mother, the sign is an indication that Wil is about to exit the closet, after her encounter with Vivian.

Another scene in which Vivian is teaching Wil "how to fall without hurting yourself", vividly demonstrates the battle raging inside Wil. The scene is set in Vivian's apartment: the room setting creates a warm and intimate atmosphere. Wil is sitting on the couch checking Vivian's photo. Her body position indicates that she is not completely relaxed. The camera captures Wil's look and smile, and then Vivian appears in the frame with a box of cookies. Moving from a medium to long shot, the camera begins to slowly follow the back of Vivian. Through Wil's point of view, the camera shows a long shot of Vivian opening the balcony. The completely enclosed room is now open to the outside. Vivian's act of opening the door is symbolic. Being presented with a wide-open view, Wil is guided into an unknown world - the one outside the closet. The gesture of opening the window thus leads to liberation and enlightenment. In this moment, we recognise the prelude to Wil's ultimate coming out.

In the same sequence, after Vivian demonstrates how to fall without hurting oneself, Wil is too awkward to practice. The angle of the camera places the two characters in the center of the frame facing each other. While Vivian's body is rather relaxed and soft, Wil's appears to be stiff. With a medium shot, the film shows Vivian holding Wil's arms and opening them next to her sides. The following scene shows that Vivian leans forward and 
gets very close to Wil's body, and then all of a sudden Wil falls. Wil chooses to fall to reject the intense sexual attraction.

To shoot their first intimate body contact, Wu uses different camera angles, inside and outside the apartment. Placed outside the apartment, the camera cuts to a long shot to show Wil practicing how to fall; the next shot is taken from inside the apartment, and in a medium shot Vivian is shown to fall after Wil. The camera then adopts a high-angle close-up shot looking down at the two characters lying close together side-by-side. The camera lingers on them, their eyes clinging to each other and their bodies slowly leaning towards each other.

The intercutting of shots inside and outside the apartment is meaningful and should be stressed, as this is emphasising the characters' isolation in at least two senses. First, there is the isolation from the rest of the world that the two lesbian lovers feel when they are together. Second, despite their closeness, the two lovers are still separated from each other due to the different views framed within and outside the closet. Clearly, Vivian is not confined to the closet, as she keeps her sexuality open to her friends and family. Wil on the other hand, is still a closeted woman in many respects, even though she has come to acknowledge their mutual attraction.

The difference between the closeted Wil and the expressive Vivian is explained through an intimate scene. In a high-angle shot, the camera looks down on Vivian, who rests her head on Wil's body. She says, "I can hear your stomach." "What does it say?” Wil asks. Vivian smiles, "Blub, blub, it's not very articulate." When asked about hers, Vivian replies proudly, "Mine sings arias [...] spouts poetry, proofs." What emerges from the intimate conversation in a closed environment is Vivian's perception of Wil: someone who is too burdened by her imposed sexual and ethnic identity to express herself fully.

Not only the dilemma embodied in the character of Wil helps construct and deconstruct the closet, but the audience at the same time is reminded of the existence of the closet by Wu's strategic use of small everyday objects such as the telephone and beeper. These items, frequently used in this film, serve as the closet or the "summons". It indicates either the distance between the two bodies or the interruption of an intimate moment. As such, it provides the closet in Wil's life with her girlfriend Vivian and jeopardises their relationship; as Vivian says at the airport, "between your mom and your beeper. I'm sick of it."

The function of the telephone in their relationship is made evident in several scenes. Let us take one of the most illuminating examples here. On the day of Vivian's birthday, the protagonists are depicted meeting in 
the park yet the fence separates their bodies. The camera captures them holding hands across the fence, and soon cuts to a shot of Wil taking her hand away after she is asked by Vivian to give her a birthday kiss. When Vivian asks Wil where she was last night, Wil's cell phone rings. The camera shows the disappointment on Vivian's face and the embarrassment on Wil's. Later, despite the clear and definite promise Wil has made in the park that she will show up at Vivian's birthday party to meet her friends who doubt Wil's existence, her plan is interrupted by urgent surgery. She is kept in the operation room for hours. The intercutting between the surgical mise-en-scène and the image of Wil holding the phone calling Vivian is a telling point: Wil's role as lesbian is again giving way to her role as a doctor.

Yet on the other hand, the telephone also serves to illustrate the lesbian intimacy and helps to create a bond, as the telephone can consolidate communication "between close relations in all the emotional, metric, sociological, demographic and economic sense of the term" ${ }^{26}$ The first intimate sexual scene takes place on the same day in Vivian's bedroom. The camera lingers on their semi-visible naked bodies and them kissing each other. In the meantime, Vivian's mom calls and leaves a message on the automatic answering machine. The audience learns that Vivian's mom is open about her daughter's lesbian relationship. The phone call draws them closer, as indicated by their sharing, giggling and physical contact.

Following her mother Ma's suggestion, when Wil rushes to the airport to persuade Vivian not to go to Paris, Vivian says to Wil, "You're too scared to look the world in the eye, and let it watch you fall in love. You're off and running without a fight." Vivian's decision to leave Wil is visualised through a shot of her disappointed face upon seeing Wil's suggestive body movement - her lowering of her head as a reaction to her last request, "Kiss me. Right here, in front of all these people." What Vivian demands from Wil is a symbolic act of coming out of the closet, a self-acceptance and reaffirmation of her gay identity, as well as the integration of her private and public identities. Being subject to the public gaze, Wil's reaction has reinforced the closet.

\section{The Ambivalent Mother Figure}

In Saving Face, Wil's mother Ma appears to the audience as both victim and victimiser, as well as both liberal and traditional. As a middle-aged Chinese widow, Ma lives in a Chinese community in New York with her parents. Her father is a respectable scholar, a community leader, and a devoted follower 
of traditional Chinese culture. As the emotional strictures imposed by ethnicity and family seem to be the least escapable ones, the figure of Ma in whom Wu places her vision for liberal change, is often shown to be trapped. Having difficulty in reconciling her own needs with family needs, she often resorts to exactly the same traditional Chinese cultural values from which she is trying to break free.

Thus, in most cases Ma is presented as a typical Chinese daughter and mother. In order to please her father, she was forced to marry a man whom she did not love, and has been a widow for many years. Like every other Chinese mother in the film, she is concerned about her daughter's clothes, marriage, and the friends she is hanging out with. The image of a Chinese mother is conveyed through specific details of Ma's interactions with Wil, Wil's black friend and neighbor Jay (Ato Essandoh), and Wil's lover Vivian. I focus on three scenes, all of which are taking place either in a Chinese restaurant or at the dinner table. The choice confirms a point that Chinese filmmakers often use food-related scenes as an important motif for crosscultural practice. ${ }^{27}$

We shall start with the dance hall/restaurant scene shown near the beginning of the film. Earlier at the hair salon where Ma works, Ma and another Chinese woman (Raymond's mother) secretly arrange a date for their children. It is noteworthy that similar to Wil and Vivian, Ma's profession is related to the body. Devoted to maximising and presenting the beauty of the body, Ma is also very concerned about her own daughter Wil's beauty and public image. From the conversation between mothers, the viewer learns that every Friday Wil comes home from Manhattan for the dance party that takes place in the restaurant in Flushing.

As agreed upon between Ma and Raymond's mother, Ma takes Wil to the dance party. Before entering the hall, Ma starts to arrange her daughter's clothes neatly. Ma's remarks on Wil's clothes - a V-neck blue shirt with dark pants - are illuminating, "I see men's clothes are still in style. Let me button that for you. People are going to think." Clearly, her idea of femininity and good behaviour are informed by the vision of traditional womanhood held by her generation. Yet the gender norms are highly contextualised, depending on time and location. This point of view is implicitly conveyed by the conflicting views of grandmother and Ma on Wil's clothes and shoes. Grandmother praises Wil's shoes over Ma's high heels, as Wil's shoes remind her of the Chinese revolution in which she was an active participant. The contrasting ideas held by Ma and her mother over what counts as suitable clothing styles suggest that the inter-generational conflict is in line with the ongoing process of social change. 
It is interesting to examine the character of Ma through her interactions with Jay, the racial “other”, and Wil's lesbian lover Vivian, the sexual "other". On the one hand, the mother figure Ma presented in Saving Face is endowed with powers so great as to affect her daughter's private life. Under Ma's will, her daughter dutifully returns home every week to attend the obligatory social event, even though Wil knows that her mother's aim is to have her meet a man. On the other hand, Ma is also experiencing an identity crisis, caught in-between two conflicting worlds, represented respectively by the strong traditions of her parents and friends and the Americanised world of Wil. Being pregnant as a Chinese widow, Ma is seen as a disgrace and is banished by her family and her friends. Thrust into Wil's world that seems unfamiliar to her, Ma has to make herself feel safe and secure. She replaces the original curtains with red ones, watches Chinese soap operas every day, and makes Chinese food at Wil's place. Her distrust of Jay and Vivian comes from both her role as a Chinese mother and as a pregnant Chinese widow.

Jay appears to be the clichéd gay friend. Being black and unable to speak Chinese, he is at first not welcomed by Ma. When Wil invites him to join them for dinner, Ma is serving Jay dinner on a paper plate, so that she will not have to touch the plate after Jay touches it with his dark skin. Ma is influenced by an idea in the minds of many East Asians that light skin is a sign of beauty and that being in contact with the dark substance will affect one's own skin. It is evident in her remark that "I should eat less soy sauce so that my baby does not get stained". She also reminds Wil to use as little soy sauce as possible as it is bad for the skin. Her comments then explain the beginning scene in which Wil is wearing a facial mask to whiten her face. The body (skin colour) forms the basis through which social class is assumed. Jay is not outwardly affected by Ma's attitude, as he smiles to Ma "thank you", and asks Wil to let her mother stay. It is then perhaps not surprising that Ma and Jay become friends at a later stage of the film. They are sitting on the couch watching Chinese TV dramas together. Meanwhile, Jay also starts to use facial masks according to Ma's suggestion. Ma's acceptance of Jay's racial and cultural difference to a certain extent is made possible by Jay's assimilation into Chinese culture.

Ma exhibits the same distrust with regard to Vivian. Even though Vivian is Chinese, her broken Chinese does not bring her closer to Ma. When Wil brings Vivian over for dinner and tells Ma that Vivian is a dancer, Ma deliberately interprets it as "wu nv" (a Chinese word referring to dancing girls, who in fact practice prostitution). Ma's demeaning of Vivian's profession epitomises the exclusion of Vivian. The interaction becomes more complicated when the camera captures Ma's look of embarrassment when 
asked by Vivian, "How is your baby doing?". Ma strategically turns to Wil and pats her, "My baby is fine, but she is too busy and I can barely see her." For Ma, the pregnancy is still a family "secret" that should not be shared with anyone outside the family, let alone discussed over dinner. When $\mathrm{Ma}$ realises the extent of Vivian's relationship with Wil, she soon shifts the topic to Vivian's boyfriend. Feeling insecure and unsafe in the presence of Jay and Vivian, as well as the larger American world they stand for, Ma tries to set up Vivian with Jay. In a way one can interpret Ma's behaviour as an attempt to exclude Vivian from Wil's life, so as to "correct" her daughter's sexual orientation. Even though Ma is aware that her daughter is a lesbian, she believes that homosexuality can be cured with proper family influence and surroundings.

Directly after her break-up with Vivian, Wil decides to disclose the "secret". She tells her mother that she loves her, but that she is also gay. In comparison with Mrs. Gao's reaction in The Wedding Banquet, Ma appears to be rather calm, "How can you say those two things at once? How can you tell me you love me, and then throw that in my face? I am not a bad mother. My daughter is not gay." Yet there is a point of similarity between these two mothers' reactions: in both cases the denial of homosexuality does not come specifically from homophobia; rather, for them, homosexuality is considered as an ethnic and cultural practice. According to Mrs. Gao's logic, her son was dating girls when he was in Taiwan, so it must be Simon - the ethnic and cultural other - who has set a bad example. Ma's logic indicates that homosexuality aligns more with bad ideology, which discards her ethnic background and family education. Both mothers attribute homosexuality to the effect of Americanisation.

At the same time, Ma is the object of blame from her father, coming from the same tradition she applies to her daughter. For Ma's father, Ma is "the biggest disgrace, the ultimate shame", and "no daughter has shamed her parents more", because of her scandalous pregnancy. Ma's refusal to reveal the identity of the baby's father makes her father furious. He yells at her, "What have we done to deserve this? When I think of all we've sacrificed in the old country, to give you kids a better life in the new one. Had I known, I would have left you behind in the mainland." Just as Ma's sorrow seems to result from heterosexual patriarchal culture, Wil too is victimised by a similar domination within Chinese family life. At a time when Ma feels the need to correct Wil's mistakes, she plays the maternal card and refers to Wil as the "ungrateful" daughter. One can note the remarks made by Ma whenever she feels disrespected, "who worked nights so you could eat? Who stayed in labor without painkillers, so you wouldn't turn dim-witted 
like your cousin Jimmy?" This is one of the typical disciplinary tactics that Chinese parents can apply. In this film, both Ma's father and Ma use emotional blackmail.

The grandmother's death serves as a turning point in the film: it drives Ma to marry a man to fulfill her father's wish, yet it also brings the mother and daughter together, when the daughter shows up to interrupt the wedding, thereby saving Ma from an unwanted marriage. As a result, the wedding is stopped, the identity of Ma's secret lover is revealed, the guests are astonished, and Ma runs away from the ceremony. It is the reconciliation of two selves inside Ma that turns her into a new woman, eventually serving to empower her daughter. It is not until she accompanies Vivian's mother to bring the separated lovers back together that she finally achieves her personal enlightenment and becomes a mother in a real sense rather than a victim or victimiser. Saving Face has placed narrative emphasis on a journey from maternal loss to regaining maternal presence.

A happy ending, however, is already hinted at through the ambivalence of the mother figure. Although Ma strives to be a good daughter and mother, she is not portrayed in traditional roles. On the contrary, she appears to be liberal and openly defies the norms set by the family and the community given the fact that she is pregnant and decides to keep the baby without revealing the father's identity. Ma's pregnancy not only functions as a dramatic element that destabilises the conservative Chinese community portrayed in the movie, but also makes the everyday mother-daughter interactions possible as it provides an ideal reason for her to move in with her daughter. Ma's autonomy over her own body is reflected first of all in her pregnancy, but secondly in maximising the range of options available to her, she enhances her body autonomy. Here I focus on one particular sequence.

Wu strategically arranges two thematically parallel stories: in the evening when Vivian takes Wil back to her apartment, Ma at the same time is also in a way breaking free from sexual repression by committing a socially "inappropriate" act of watching sexually explicit DVDs. In order to show two stories happening simultaneously, Wu alternates between the different locations: Wil and Vivian are shown together furst in a clothing shop and then in Vivian's apartment; Ma is first placed in a street and later in Wil's apartment.

The camera cuts from Wil and Vivian to Ma, following her wandering in the street. The mother is eating chips and looking around. The camera offers a medium close-up of her face, suggestive of her curiosity about the world around her. Ma wanders into a video shop asking for Chinese movies. The camera focuses on Ma's eyes and follows her gaze around the DVD 
collection on the shelf. What appear in the frame are The Last Emperor (in which Joan Chen was cast in a major role), The Joy Luck Club and some Asian pornography.

The interesting part begins when Ma stops in front of the pornographic movies: she looks first to the left and then to the right. After some hesitation, she disappears from the frame and appears again. Wu intercuts from close-up shots of Wil and Vivian kissing in Vivian's apartment to a long shot of Ma sitting on the couch watching television. The camera zooms in and focuses on Ma holding the cushion tightly. The director leaves the image that Ma is watching off screen, yet keeps the diegetic sound, "Who is your Asian daddy?". At this moment, the audience realises that Ma has rented a pornographic film.

In her essay "Film Bodies: Gender, Genre, and Excess", Linda Williams categorises porn, horror and melodrama as "body genres". As she suggests, the pornographic film strives to move the spectator to sexual arousal. As a result, the body of the spectator is caught up in mimicking the sensationally displayed bodies on the screen. In Hard Core: Power, Pleasure and the Frenzy of the Visible', Williams argues, "pornography [has] long been a myth of sexual pleasure told from the point of view of men with the power to exploit and objectify the sexuality of women" ${ }^{28}$ While porn is traditionally made for men and about women, women can also appropriate the dominant form of heterosexual pornography for their own readings. As McNair says, "in the private worlds of fantasy and sexual relationships [...] women have increasingly used pornography - subversively decoding male-orientated material on the one hand, consuming material produced by women for women on the other". ${ }^{29}$ Therefore, by depicting Ma walking into the video shop under the male gaze, and watching sexual scenes in the movie she rents, the film suggests that the mother has reclaimed autonomy over her own body.

The values Ma embodies are socially constructed but at the same time they are in constant negotiation and interaction by the individual and group. Cultural life in the Chinese-American community does not remain static; instead, it underlies a process of constant formation and change due to new cultural influences. To further illustrate this point, I compare the concluding sequence with a dance party sequence near the beginning of the film; both are taking place in the dance hall in the Chinese restaurant consisting of almost the same group of people. 


\section{The Chinese-American Community in a Changing Cultural Context}

The first of the two selected sequences provides the location where Wil first meets Vivian, although later we learn that Vivian has remembered an encounter with Wil from when she was eight years old. The closing sequence is meant to reunite the two lovers. The final scene deliberately echoes the earlier scene. In the first scene both Wil and her date Raymond are aware that their mothers have tried to set them up, yet they are willing to play the game, which offers two points: on the one hand, Raymond attempts to protect Wil from the Chinese community that is not ready to accept Wil's homosexuality; on the other hand, by introducing Wil to Vivian through Raymond, the encounter between Wil and Vivian in the future is predicted. Wil and Raymond, while striving to satisfy their parents, seek to fulfill their own needs outside the traditional family roles. The ideology of holding the family together also explains why the grandfather is forced to accept the unconventional relationships of Wil and Ma in the closing scene. A comparison of these two sequences demonstrates the restructuring of the Chinese community that is at once defined and shaped by traditional patriarchy, heterosexuality, and family-kinship systems. Thus, the film Saving Face can indeed be read as a progressive project, idealistic as it is.

The mise-en-scène suggests that the dance party is defined in an explicitly heterosexual and ethnic manner. First of all, the dancehall - a performing stage - evokes a sense of collective identity, as the group exclusively consists of Chinese participants. This explains why Mrs. Wong is upset when her son Raymond is dating a white girl. Nevertheless, the mixed use of English and Chinese at the party suggests the "hybrid" nature of the community, and the possibility of breaking down the old ethnic and cultural exclusiveness.

Second, through framing and editing, the filmmaker hints at the social reinforcement of heterosexual boundaries. The social separation of men and women is conveyed visually. The camera switches between shots with only men and shots with only women, indicating that both occupy different spaces and are socially separated. The two groups face each other. The editing creates an opposition between male and female groups. After the camera alternates a few times between the long and medium shot, between all-female and all-male groups, it cuts to a medium close-up of Ma's face, who obviously is embarrassed by the discussion of a group of Chinese women about the divorce of Vivian's mother. Other Chinese women surround $\mathrm{Ma}$, as if she were one of them, yet the isolated shot singles her out 
from the rest. In this respect, the display of the scenes at the dance hall has added a further dimension to the identification with others.

The heterosexually-defined community is visually constructed by the dancing couples. Davis summarises that "dance is commonly described as a courtship activity, as a means of getting sex, or as a male predatory activity." ${ }^{30}$ Ward points out that "dance is not just a means to sex (although of course it may be such) but [...] is or can be a form of sexual expression in itself." ${ }^{31}$ Unsurprisingly, the dance area functions as a stage on which the "performance" of the participants constitutes their subjectivity and their sexual identity. They are placed under the social gaze. Thus, one can see that only the opposite sex couples are dancing here and the heterosexist assumption is implied and emphasised in the scene. Clearly Wil and her male dancing partner are playing along with the rules.

Third, ideologically speaking, the notion of inclusion and exclusion is applied, in order to perpetuate the binary opposition of heterosexualityhomosexuality, male-female, and Chinese-American. While the camera switches between different groups, it also gives a single isolated long shot of Jenny, Vivian's divorced mother, who is sitting alone. The long shot distances Jenny in the far background. The fact that she is left alone suggests that she is different from the group, as illustrated by the remark made by a woman in the group, "Why be like those Americans, divorcing all the time?" The collective body of values and beliefs by which the ethnic Chinese group is defined and identified is challenged by Jenny and her divorce, subsequently alienating her from the group.

If the beginning of the film more or less shows a clearly defined set of social rules that are meant to protect ethnic traditions, the closing sequence serves to challenge the assertion of social norms and eliminate the traditional restrictions placed on the ethnic group and family relationships. In the closing scene, the basic assumption that everyone should be heterosexual is broken, signified by the fact that two female characters are shown dancing together. Their climactic reunification kiss implies a symbolic homecoming for Wil, who is no longer following the rules of the heterosexual social contract. Eventually she comes out of the closet. The grandfather who holds on to Chinese values against American culture appears to be a defeated patriarchal figure. In response to the remark by a Chinese man that "the world is getting too hard to predict", he says, "It just keeps getting worse."

The film presents a compassionate view of lesbian relationships and the Chinese community in transition: some participants leave the dance hall, but some choose to stay and to dance to the music. The reputation 
and face of the family as a collective unit - which functions as the main self-governing mechanism in the Chinese context - is challenged by the individualisation and empowerment of women as well as by the changing social and cultural context. The exploration of gender and sexual identities is contained mainly in the stories of Wil and Ma, yet the effort to empower less privileged groups such as women and homosexuals is complex in the sense that it involves several female characters - grandmother, Ma, Jenny, Wil, and Vivian - that are from three different generations and are shaped by different cultural and social factors. Nevertheless, the negotiation of family face is ongoing, as suggested by the closing lines of the film. The grandfather is not off the stage, as he speaks, "the moment that girl is born, I'm coming over every day. God knows how she'll turn out if she's brought up by you two."

My reading of the movie Saving Face reveals the way in which contemporary transnational Chinese film is using family conflicts involving three generations to illustrate how sexuality can pose a challenge to the traditional Chinese cultural norm of family face. Wil and Ma are both torn between the demands of preserving traditional ethnic culture and their desire for increased individual autonomy and sexual freedoms. The ethical dilemma or conflict confronted by Wil and Ma simultaneously forms the narrative-thematic core of family melodrama. It is argued that the triangle relations among Wil, Ma, and Vivian play a crucial role in the achievement of personhood and the empowerment of the female characters. The progressive liberating process of coming out of the closet embraced by Ma and Wil in the end also invokes cultural change in the Chinese-American community.

\section{Conclusion}

It is important to emphasise that the family melodrama in transnational Chinese cinema functions as a bridge to explain the unexplainable in crosscultural encounters. By making it necessary to ask "What has defined the Chinese American?" the films make us understand that the representation of ethnic culture and identity has been shaped, defined, and informed by individual experiences. Analysis of Chinese-American experiences shows us that there is no essential Chineseness, only multiple ways of being Chinese. As such, Chineseness has never been a singular form; rather, it has a plural content that is related to individual experiences. The cinematic representation of family experiences and the pathos that so often accompanies 
them reflects what Berry and Farquhar have termed as the mixed mode of "melodramatic realism." ${ }^{32}$ It echoes the point made by Nowell-Smith that "the basic conventions of the melodrama are those of realism: i.e., what is represented consists of supposedly real events, seen either 'objectively' or as the summation of various discrete individual points of view." ${ }^{33}$ The family melodramas, especially those dealing with family conflict in the migration context, have turned the narrative mode into a more realistic style to elucidate the experiences of the Chinese American caught up in remarkable and rapid changes. The representation of family conflict to a large extent confronts sociopolitical complications and influences viewers in real life, by giving the spectator "the opportunity to see meanings represented, emotions and moral states rendered in clear visible sign." ${ }^{34}$ Melodrama can thus be seen as a nexus where certain determinations (such as family, immigration, and identity) are brought together. The binary opposition of modernity against traditional family structure and values is instead through the melodramatic form made less clear and more flexible. In my comparison of the two films, individualism and self-affirmation are presented as elements of the modernisation process, yet in fact what guides the characters' actions in relation to those around them is their capacity to perform compromise. Over the past thirty years, a tradition of using melodrama to depict the Chinese-American family has shown us a negotiated modernity, and at the same time, a negotiated sense of tradition.

\section{Notes}

1. I use "Chinese" in its broad sense without making a distinction between Chinese from Mainland China, Taiwan, Hong Kong, and overseas, although I am aware of the fact that being Chinese is culturally multiple and hybrid. Likewise, it is important to keep in mind that the term Chinese American used in this article does not in any sense imply that Chinese Americans are a monolithic group, since the Chinese-American community consists of people from various backgrounds, sharing different experiences. It also makes a difference as to whether the individual or household under study has already been settled as the second or third generation. Thus, the application of the term "Chinese American" should not deny the extent to which individual Chinese Americans identify with their ethnic group. Five major types of Chinese-American identity have been identified:yeluo guigen (fallen leaves return to the roots, or immigrants' desire to return to China but may only be buried there), zancao chugen (total assimilation), luodishenggen (accommodation), xungen wenzu (ethnic pride, or search for one's roots), and shigen lizu (uprooted, or losing contact with one's roots). For an elucidation of this typology see Ling-chi Wang, "Roots and Changing Identity of the Chinese in the United States", Daedalus 120 (1991): 181-207. The transnational nature of "Chineseness" should be recognised, moving beyond the conventional construction of the "political China" further complicated by the historically separated territories and polities 
of Hong Kong, Taiwan and Mainland China. In relation to the concept of "cultural China" see Weiming Tu, "Cultural China: The Periphery as the Center", in The Living Tree: The Changing Meaning of Being Chinese Today, ed. Weiming Tu (Stanford: Stanford University Press, 1994), 1-17. The transnational ethnicisation of Chineseness both encompasses and transcends Chineseness defined on ethnic, territorial, linguistic and religious grounds, and for $\mathrm{Tu}$, the Chinese diaspora as the periphery constitutes a new cultural center of Chineseness. The interface between "Chinese" and the "Chinese overseas" has produced a transnational Chinese imagination, which is a staging ground for acting rather than an escape. Thus, insights into the concept of "transnational" allow us to move toward ethnic transnationalism, calling for a shared identity and a sense of mutual belonging. In so doing, migrants are able to mobilise ethnic ties without being confined to ethnic stratification.

2. While the term melodrama entails different meanings, it has gained a more stable definition in the field of film studies. Peter Brooks has characterised melodrama as the "theatrical impulse itself: the impulse towards dramatization, heightening, expression, acting out"; see Peter Brooks, The Melodramatic Imagination:Balzac, HenryJames, Melodrama, and the Mode of Excess (New Haven: Yale University Press, 1976), xv. Melodrama should be understood as a drama of "excess", a modern form and a mode of "high emotionalism and stark ethical conflict that is neither comic nor tragic"; see Brooks, Melodramatic Imagination, 12.

3. Brooks, Melodramatic Imagination.

4. Chris Berry, "Wedding Banquet: A Family (Melodrama) Affair," in Chinese Films in Focus: New Takes, ed. Chris Berry (London: British Film Institute Publishing, 2003), 183-90; Chris Berry \& Mary Ann Farquhar, China on Screen: Cinema and Nation (New York: Columbia University Press, 2006).

5. It has been suggested that the standard Chinese translation of "melodrama" should be "jiating lunlipian (family ethics film)"; see Berry \& Farquhar, China on Screen, 243.

6. Berry, "Wedding Banquet," 186.

7. Ongoing cultural change and the logic of modernity served to steer the process of change. Influenced by the May Fourth demonstrations in 1919 and the accompanying New Culture Movement, many Chinese intellectuals of this time were seriously reflecting on traditional Confucian morality and called for reforms in the social structure. As a result, many values and customs taken for granted such as the hierarchical and patriarchal structure of the family, arranged marriage, and filial piety, were criticised. See Qijun Han, "Melodrama as Vernacular Modernism in China: The Case of D. W. Griffith," Scope: An Online Journal of Film Studies (forthcoming 2013).

8. Ang Lee's parents were from Mainland China but during the Chinese Civil War they moved to Taiwan where Lee was born and raised in accordance with traditional Chinese cultural ways. After Lee completed his Bachelor's degree in theater in the United States where he is mostly based, he was able to function as a director with the support of transnational capital, crew, and markets - especially from Taiwan, Mainland China and the United States. Alice Wu is a second-generation Chinese woman who was born, raised and educated in the United States.

9. Hwee Lim Song, Celluloid Comrades: Representations of Male Homosexuality in Contemporary Chinese Cinemas (Honolulu: University of Hawaii Press, 2006); Helen Hok-Sze Leung, Undercurrent: Queer Culture and Postcolonial Hong Kong (Hong Kong: Hong Kong University Press, 2008); Fran Martin, Situating Sexualities: Queer Representation in Taiwanese Fiction, Film and Public Culture (Hong Kong: Hong Kong University Press, 2003).

10. Dariotis Ming \& Eileen Fung, "Breaking the Soy Sauce Jar: Diaspora and Displacement in the Films of Ang Lee," in Transnational Chinese Cinema:Identity, Nationhood, Gender, ed. Sheldon Lu and Hsiao-peng Lu (Honolulu: University of Hawaii Press, 1997), 187-218. Shu-mei Shih, "Globalization and Minoritization: Ang Lee and the Politics of Flexibility," New Formations 
40 (2000): 86-101; Gina Marchetti, "The Wedding Banquet: Global Chinese Cinema and the Asian American Experience," in Countervisions: Asian American Film Criticism, ed. Darrell Y. Hamamoto and Sandra Liu (Philadelphia: Temple UP, 20oo), 274-97. Fran Martin, "Globally Chinese at The Wedding Banquet," in Situating Sexualities, 145; Jeroen de Kloet, "Saved by Betrayal? Ang Lee's Translations of 'Chinese' Family Ideology," in Shooting the Family: Transnational Media and Intercultural Values, ed. Patricia Pisters and Wim Staat (Amsterdam: Amsterdam University Press, 2005), 117-32; Hwee Lim Song, "The Burden of Representation: Ang Lee's The Wedding Banquet," in Celluloid Comrades, 41-68; Berry \& Farquhar, China on Screen.

11. Connie Chan, "Issues of Identity Development among Asian-American Lesbians and Gay Men," Journal of Counseling and Development 68 (1989): 16-21.

12. Bret Hinsch, Passions of the Cut Sleeve: The Male Homosexual Tradition in China (Berkeley and Los Angeles: University of California Press, 1990); Franklin Ng, Asian American Family Life and Community (London: Routledge, 1998).

13. Shumei Shih, Visuality and Identity: Sinophone Articulations across the Pacific (Berkeley: University of California Press, 2007), 49.

14. There has been a long tradition in Hollywood of reducing cultural outsiders to stereotypes. Espiritu concludes that there are four controlling images for the social construction of Asianness referring in turn to Yellow Peril, the Model Minority, the Dragon Lady, and the China Doll; see Yen Le Espiritu, Asian American Panethnicity: Bridging Institutions and Identities (Philadelphia: Temple University Press, 1992). In Orientals, Lee sums up six modern stereotypes with regard to the construction of Asian Americans, defined as follows: "pollutant, the coolie, the deviant, the yellow peril, the model minority, and the gook"; see Robert Lee, Orientals: Asian Americans in Popular Culture (Philadelphia: Temple University Press, 1999); Scholarship on the subject of stereotyping Chinese can also be found in Richard A. Oehling, "The Yellow Menace: Asian Images in American Film”, in The Kaleidoscopic Lens: How Hollywood Views Ethnic Groups, ed. Randall M. Miller(Englewood, NJ: Jerome S. Ozer Publisher, 1980), 182-205; Brigit Zinzius, Chinese America: Stereotype and Reality: History, Present, and Future of the Chinese Americans (New York: Peter Lang Publishing, 2005); Urmilla Seshagiri, Race and the Modernist Imagination (Ithaca: Cornell University Press, 2010).

15. Simon overhears the conversation between Wai Tung and his mother. He therefore knows that Wai Tung has come out of the closet but the news could put the father's life at risk.

16. Ming \& Fung, "Breaking the Soy Sauce Jar," 203-06.

17. Shih, "Globalization," 96.

18. Berry \& Farquhar, China on Screen, 179.

19. De Kloet, "Saved by Betrayal?".

20. Rey Chow, Sentimental Fabulations, Contemporary Chinese Films: Attachment in the Age of Global Visibility (New York: Columbia University Press, 2007), 142.

21. Chow, Sentimental Fabulations, 140; Martin, Situating Sexualities, 145.

22. Stephen Holden, "Juggling Her Chinese Clan, Gay Lover, Pregnant Mom", review of Saving Face, by Alice Wu, New York Times, May 27, 2005, accessed November 4, 2013. http://www. nytimes.com/2005/05/27/movies/27face.html?_r=o.

23. Song-Mei Lee-Wong, Politeness and Face in Chinese Culture (Frankfurt: Peter Lang, 1999).

24. Steven Seidman, Beyond the Closet: The Transformation of Gay and Lesbian Life (New York: Routledge, 2004), 255.

25. Michelle Brown, Closet Space: Geographies of Metaphor from the Body to the Globe (London: Routledge, 2000), 1.

26. David Morley, Home Territories: Media, Mobility and Identity (London: Routledge, 200o), 98. 
27. Chinese food is more or less universally associated with "Chineseness". It is, therefore, not surprising to see that filmmakers make use of this important "Chinese" motif as a cross-cultural practice. A Chinese restaurant, food or dining scenes are very frequently presented in transnational Chinese family melodramas. Such an arrangement, of course, has to do with the significant role played by food in the imaginary of Chinese culture; but on the other hand, it also points to the idea that melodrama foregrounds everyday life in its modes of storytelling. In this respect, food conveys a strong sense of daily practice. Anne Bower argues for the importance of food symbolism in movies as follows, "movie viewers respond so readily to food imagery because of food's primacy in our lives; it is a primacy that precedes literacy but then becomes part of our symbol-making, symbol-decoding capacity" (Bower, 2004: 10). See Anne Bower, ed., Reel Food: Essays on Food and Film (New York: Routledge, 2004).

28. Linda Williams, Hard Core: Power, Pleasure, and the "Frenzy of the Visible" (London: Pandora, 1990), 22.

29. Brian McNair, Mediated Sex: Pornography and Postmodern Culture (New York: Arnold, 1996), 129 .

30. Deborah Davis, The Consumer Revolution in Urban China (Berkeley \& Los Angeles: University of California Press, 2000), 228-9.

31. Andrew H. Ward, "Dancing in the Dark: Rationalism and the Neglect of Social Dance," in Dance, Gender and Culture, ed. Helen Thomas (London: Macmillan, 1993), 16-33.

32. Berry \& Farquhar, China on Screen, 76 .

33. Geoffrey Nowell-Smith, "Minnelli and Melodrama," in Home is Where the Heart Is, ed. Christine Gledhill (London: British Film Institute, 1991), 70-4.

34. Brooks, Melodramatic Imagination, 62.

\section{About the Author}

Qijun Han has a BA (with honors) from Nanjing University, majoring in English studies, and has an MA in American Studies from Utrecht University. From 2009 to 2013, she has carried out her PhD at the Research Institute for History and Culture, also at Utrecht University. During this time, she completed a thesis entitled "The Ties That Bind: The Chinese-American Family in Transnational Chinese Cinema", examining the cinematic construction of Chinese identities in the United States. She has published several articles on Chinese family culture, the cinematic representation of Chinese family conflict in the migration context, and Chinese cinema in the 1920s. Email: Q.Han@uu.nl.

\section{(c) (i) ()ㅇ}

2013 Han / Amsterdam University Press.

This is an Open Access article distributed under the terms of the Creative Commons Attribution License (http:// creativecommons.org/licenses/by/2.o), which permits unrestricted use, distribution, and reproduction in any medium, provided the original work is properly cited. 